\title{
The Influence of Neuroendocrine and Sleep Disturbances on Recovery from Traumatic Brain Injury
}

\author{
Howell SN ${ }^{1}$, Kreber LA ${ }^{1 *}$, Ashley J G ${ }^{1}$ and \\ Griesbach GS $\mathbf{1}^{1,2}$ \\ ${ }^{1}$ Centre for Neuro Skills, Bakersfield, CA, USA \\ ${ }^{2}$ Department of Neurosurgery, David Geffen School of \\ Medicine at UCLA, Los Angeles, California, USA \\ *Corresponding author: Lisa Kreber, Centre for \\ Neuro Skills, Research Department, 5215 Ashe Road, \\ Bakersfield, CA 93313, USA
}

Received: August 28, 2017; Accepted: September 26, 2017; Published: October 03, 2017

\begin{abstract}
This article describes the relationship between sleep and neuroendocrine disorders following traumatic brain injury (TBI). There is evidence to support that sleep disorders and neuroendocrine dysfunction can negatively impact recovery and may be the underlying cause of some of the physical, cognitive and emotional symptoms experienced by patients following TBI. We will address the impact of TBI on the neuroendocrine system and sleep-wake cycles within the context of rehabilitation. Specifically, we will focus on the effects of TBl-induced neuroendocrine and sleep alterations and the influences these disorders have on rehabilitation outcomes. Findings from non-injured and injured patient populations are reviewed and support diagnosing and treating sleep disturbances and neuroendocrine dysfunction while the patient is undergoing rehabilitation. A better understanding of the interplay between neuroendocrine functioning and sleep may improve quality of life and rehabilitative outcomes after TBI.
\end{abstract}

Keywords: Traumatic Brain Injury; Rehabilitation; Outcome; Neuroendocrine Dysfunction; Sleep-Wake Disturbances

\section{Introduction}

The sequelae of chronic traumatic brain injury (TBI) have long term consequences that are addressed within the post-acute rehabilitation setting. Some of these include issues with memory, attention, balance, coordination, and emotional regulation [1]. A better understanding of the underlying mechanisms responsible for these issues is likely to maximize a patient's recovery. Both sleep and neuroendocrine disorders have been observed following TBI and have been linked to multiple factors that contribute to disability. Disturbances in sleep and neuroendocrine dysfunction have been associated with cognitive impairments including attention, memory and executive function as well as emotional regulation and fatigue [2-6].

This article will describe what is currently known about sleep and neuroendocrine function following TBI. More specifically, the effect of alterations in these systems on chronic outcome will be described. This article will also address the assessment, diagnosis and treatment of sleep and neuroendocrine disorders within the post-acute rehabilitative setting. The ability to detect and treat sleep and neuroendocrine abnormalities can impact the responsiveness to rehabilitation.

\section{Neuroendocrine Function and TBI}

\section{Impact of TBI on the neuroendocrine system}

Neuroendocrine dysfunction following TBI is not a rare phenomenon and has been investigated in both the acute and chronic phases of rehabilitation [3,7-15].

Structural damage to the neuroendocrine system may be caused by TBI induced white matter damage; thus affecting connectivity in hypothalamic and supra hypothalamic structures. Two-thirds of individuals at autopsy who did not survive their TBI were found to have structural abnormalities of the pituitary, pituitary stalk and/or hypothalamus $[16,17]$. On a cellular level, the somatotroph cells in the anterior pituitary, which produce growth hormone (GH), and the gondatroph cells, which produce luteinizing hormone (LH) and follicle stimulating hormone (FSH), are vulnerable to damage due to their location in the outer wings of the pituitary lobe and their relatively fragile blood supply [7]. Consistent with this observation, $\mathrm{GH}$ and testosterone are the most commonly deficient hormones following TBI [10,18-21]. Corticotrophic and thyrotrophic cells are less vulnerable to injury given their more central location within the anterior pituitary lobe [7]. These findings are also supported with prevalence studies that indicate that cortisol and thyroid hormones are often less affected following brain trauma $[3,10,22]$. These findings are not surprising given that low cortisol is associated with increased mortality in patients with moderate to severe TBI (and thus, these individuals may succumb to their injuries prior to being screened for hypoadrenalism) [23]. There is a relative paucity of literature on chronic hypocortisolism, perhaps due to more detectable symptoms and no controversy surrounding cortisol replacement [24].

Prevalence studies of neuroendocrine dysfunction following TBI estimates incidence between 35 to $68 \%$ (Table 1). This variability may be due to methodological differences between studies such as patient selection (e.g. age of the patients and injury severity), timing of testing post-TBI, protocols for evaluating hormone levels (i.e. whether a provocative test was used or not), and confounding effects of medications and nutritional status [25].

Hypopituitarism following TBI is a dynamic process, with some hormone deficiencies resolving over time, and other deficiencies emerging over time [12,26-30]. Aimaretti and colleagues examined pituitary hormone levels in patients with mild, moderate, and severe 
Table 1: Prevalence of Neuroendocrine Dysfunction Following TBI.

\begin{tabular}{|c|c|c|c|c|c|c|c|c|}
\hline Author & $\begin{array}{l}\text { Number of } \\
\text { Participants }\end{array}$ & $\begin{array}{c}\text { Age } \\
\text { (years) }\end{array}$ & Time Since TBI & $\begin{array}{c}\text { Prevalence of Neuroendocrine } \\
\text { Dysfunction (\%) }\end{array}$ & $\begin{array}{c}\text { GH axis } \\
\text { Deficiency (\%) }\end{array}$ & $\begin{array}{l}\text { Gonadal } \\
\text { axis } \\
\text { Deficiency } \\
\text { (\%) }\end{array}$ & $\begin{array}{l}\text { Thyroid } \\
\text { axis } \\
\text { Deficiency } \\
\text { (\%) }\end{array}$ & $\begin{array}{l}\text { Adrenal } \\
\text { axis } \\
\text { Deficiency } \\
\text { (\%) }\end{array}$ \\
\hline Kelly et al., 2000 & 22 & $20-52$ & 3 months- 23 years & 36.4 & 18.2 & 22.7 & 4.5 & 4.5 \\
\hline Lieberman et al., 2001 & 70 & $18-58$ & 1 month-23 years & 68.5 & 14.6 & 1 & 21.7 & 45.7 \\
\hline Bondanelli et al., 2004 & 50 & $20-87$ & $1-5$ years & 54 & 28 & 14 & 10 & 0 \\
\hline Agha et al., 2006 & 102 & $15-65$ & 6-36 months & 28.4 & 17.6 & 11.8 & 1 & 22.5 \\
\hline Nemes et al., 2015 & 126 & 42.4 & 48 months & 57.1 & 39.7 & 23 & 16.7 & 10.3 \\
\hline Nemes et al., 2016 & 63 & 37.5 & 1.1 years & 68.3 & 50.8 & 23.8 & 22.2 & 9.5 \\
\hline
\end{tabular}

$\mathrm{GH}$ : Growth Hormone.

levels of TBI at 3-months and 12-months post-injury [12]. Pituitary dysfunction was found in $32.8 \%$ of patients at 3 months and $22.7 \%$ of patients at 1 year. Seventy-five percent of the patients with single or multiple axis abnormalities at 3 months had returned to normal at 12 months. Conversely, $6 \%$ of patients who had normal pituitary hormone levels at baseline developed single axis pituitary dysfunction at 1 year, and $13 \%$ who had single axis deficiencies at 3 months had developed multiple deficiencies at 1 year. Interestingly, of the 32 patients with a mild TBI, 13 had chronic pituitary deficiencies, suggesting that the incidence of neuroendocrine dysfunction in mild TBI is considerable. Krahulik and colleagues followed 89 patients with post-traumatic pituitary dysfunction over time and discovered that $21 \%$ had developed neuroendocrine dysfunction [30]. Deficits in GH were most common, followed by hypogonadism. Schneider and colleagues reviewed the prevalence of pituitary dysfunction in 825 participants who were at least 5 months post-injury [28]. At least one hormonal abnormality was present in $38 \%$ of patients. The prevalence of post-traumatic pituitary dysfunction in individuals with mild, moderate, and severe TBI was $16.8,10.9$, and $35.3 \%$, respectively; again demonstrating individuals with a less severe TBI are still at risk for developing hormonal deficiencies. Krahulik and colleagues observed that patients who recovered their normal axis function over time, and patients who were normal at the time of injury (or at 3 months post-injury), subsequently developed post-traumatic pituitary dysfunction [30]. These studies clearly suggest that early pituitary deficits may recover over time, and that conversely, normal pituitary function early after injury may become abnormal at 3-12 months. Recovery does not appear to occur in patients who develop deficiencies of all pituitary hormones (i.e., panhypopituitarism).

Taken together, it appears that at approximately 6-months post TBI, hormone deficits appear to be stable and relatively permanent [31]. Due to the fluctuations in hormone levels following TBI, consensus guidelines from the American Association of Clinical Endocrinologists and American College of Endocrinology have recommended that all patients with moderate to severe TBI be assessed for neuroendocrine dysfunction during the acute and chronic phases of their recovery $[23,25]$ and patients with mild TBI who are experiencing symptoms should be offered hormone assessment $[18,25,32]$. An algorithm for the timing of a baseline hormone workup has been proposed by Ghigo and colleagues, and is as follows: For all TBI patients, regardless of severity, hormone assessments should be conducted during hospitalization, especially if hyponatremia and hypotension are present [18]. Assessments should be repeated at 3 and 12 months after any severity of TBI. Retrospectively, if patients with TBI have any signs or symptoms of hormone dysfunction, and are at least 12-month post-TBI, immediate hormone testing should be conducted, as it is unlikely that any hormone deficiencies are transient at this point [18]. Agha and colleagues proposed that morning cortisol levels be assessed 1-7 days post-TBI and treatment with glucocorticoids be initiated if a deficiency is observed [13]. They proposed re-assessment of anterior pituitary hormones in the postacute phase of recovery (3-6 months post-TBI).

\section{Effects of TBI-Induced neuroendocrine alterations}

Neuroendocrine dysfunction following brain injury has been associated with adverse effects in patients in the acute or chronic stages [33-37]. Post-traumatic pituitary dysfunction has been linked to reduced quality of life and rehabilitation outcomes with direct adverse effects on health outcomes including ischemic heart disease and shortened life span [38-40]. Understanding the signs and symptoms of hormone deficiency may assist in the timely diagnosis of and treatment of hypopituitarism. Clinical symptoms associated with hypopituitarism are dependent on the specific hormone axis affected, severity of the hormone deficiency, gender, and whether the deficiency is transient or permanent.

In healthy adults the gonadal hormones have been associated with cognitive functioning. Specifically, higher levels of LH have been associated with lower cognitive performance [41,42] whereas higher levels of FSH have been associated with preserved cognitive functioning [41]. Although estrogen and testosterone decline with age, these hormones are associated with memory and overall cognitive functioning $[43,44]$. Higher levels of testosterone have been associated with increased verbal and visual memory, as well as attention [44,45], and estrogen replacement has been associated with improved cognitive functioning in women [46,47]. The cognitive effects of thyroid deficiency include slowed speed of information processing, executive functioning deficits, impaired attention, and deficits in visual and verbal memory $[48,49]$. These deficits significantly overlap with those of TBI. Similarly, cognitive effects of growth hormone deficiency (GHD) in individuals without TBI include memory impairment, difficulty concentrating, and decreased IQ $[3,50]$.

Neuroendocrine dysfunction has been associated with significant negative consequences in physical and metabolic functioning. The 
effects of hormone deficiency may potentially impede progress in rehabilitation, impair recovery and may even contribute to significant morbidity following TBI. Physical manifestations of glucocorticoid deficiency can include fatigue, pallor, myopathy, anorexia/weight loss, weakness, hypotension, nausea and hypoglycemia [39]. Some of the symptoms of a glucocorticoid deficiency overlap with those of a thyroid deficiency, specifically fatigue and myopathy. Other clinical indicators of thyroid deficiency include cold intolerance, constipation, weight gain, hair loss, dry skin, bradycardia, and hoarseness [26, 39]. Hypogonadism has been associated with adverse effects on reproductive functioning including infertility, decreased libido and impaired sexual function [51]. Physical symptoms of hypogonadism specific to women include ammenorrhea, osteoporosis, and premature atherosclerosis [51]. Testosterone deficiency in men is associated with decreased muscle and bone mass, erythropoiesis, hair growth, decreased energy, and impaired exercise tolerance [27]. If left untreated, hypogonadism can cause premature mortality secondary to cardiovascular disease [52]. Untreated adult onset GHD presents clinically as abnormal body composition, specifically decreased muscle mass [53], altered bone metabolism [54] and greater body fat [55] in conjunction with decreased exercise capacity, [38], fatigue [55] low energy, increased insulin resistance and unfavorable lipid profile [55]. Due to its adverse effects on metabolism and cardiovascular function [56] GHD may increase the risk of mortality [36,52,57,58].

Deficiencies in growth hormone, thyroid, corticosteriods and sex hormones have been associated with poor quality of life $[59,60]$. Maladaptive behaviors and affective disturbances are prevalent after TBI and can influence rehabilitation participation and functional outcomes [37,61-63]. Specifically, depression [3,18,50,64] and irritability [65] have been associated with hormone deficiencies. It has been difficult to parse out the effects of post-TBI depression and anxiety from that caused by neuroendocrine dysfunction. Prevalence rates of post-TBI depression are estimated to be $30-38 \%$ [66]. Pain, fatigue, sleep disturbance, cognitive dysfunction, apathy, decreased mobility, and emotional processing deficits can be present following TBI and may result in depression by themselves, or may have a cumulative effect with neuroendocrine dysfunction or the TBI itself.

From the discussion of hormones and their effects on functioning, it is easy to see how many of the symptoms of pituitary dysfunction significantly overlap with symptoms of brain injury. As such, a diagnosis of neuroendocrine dysfunction following brain injury is often missed. For instance, memory impairments, anxiety, depression, social isolation, deterioration in sex life, fatigue and unemployment are all issues associated with isolated brain injury and isolated neuroendocrine dysfunction $[3,50]$.

\section{Diagnosing neuroendocrine dysfunction in a rehabilitation setting}

Early diagnosis of pituitary dysfunction and subsequent treatment can improve outcomes [30]; however, neuroendocrine dysfunction may be a delayed or undiagnosed condition due to masking effects of impairments secondary to TBI. The only way to truly rule out neuroendocrine dysfunction following brain injury is to screen for it. The American Association of Clinical Endocrinologists has recommended that all patients with moderate to severe traumatic brain injury (TBI) be assessed during the acute and chronic phases of their recovery [25]. Individuals who have sustained a mild TBI who are experiencing symptoms should be offered assessment [25].

Basal hormone screening involves assessing each individual axis of the pituitary separately. Serum levels of thyroid stimulating hormone (TSH) and free T4 should be measured to evaluate the thyroid axis. A diagnosis of central hypothyroidism can be made with a normal or low TSH and low levels of free T4 $[67,68]$. The gonadal axis is assessed by measuring baseline levels of FSH and LH, along with free and total testosterone levels in men and an estradiol level in pre-menopausal women, who are not menstruating regularly. Central hypogonadism can be diagnosed with low levels of testosterone or estrogens with either normal or low FSH and LH levels [20,36,69]. Prolactin levels should also be measured in both sexes, as increased levels can indicate underlying structural pathology of the pituitary $[21,67]$. Basal hormone levels for the thyroid, gonadal, and prolactin axes are sufficient for a diagnosis $[12,29,69]$. However, adrenal insufficiency and GHD may require provocative testing in addition to basal hormone screenings [3,18,25,32].

A diagnosis of adrenal insufficiency is likely to be captured in the acute phase of TBI due to the life-threatening effects of deficiencies in this hormone [59]. Determination of basal morning cortisol levels is necessary for initial screening of adrenal insufficiency. If cortisol levels are less than $500 \mathrm{nmolL}^{-1}$ in the post-acute phase of TBI, a referral to an endocrinologist is warranted for further assessment, including a dynamic stimulation test to assess adrenal reserve [3]. A provocative test of ACTH reserves is not practical in the acute setting where the factors such as sepsis and certain medications can influence the results [59]. Dynamic cortisol testing may be warranted in the post-acute phase of TBI if morning cortisol levels are deficient [25]. The cosyntropin stimulation test can directly assess adrenocortical response, and a blunted response suggests corticotropin deficiency [70]. It should be noted that it may take 6-8 weeks after TBI for patients with central hypoadrenalism to show an abnormally low response on this test [25]. Other provocative tests to evaluate adrenal function include the insulin tolerance test (ITT) and the metyrapone test, but these tests may not be practical or safe in medically unstable patients [25].

Direct serum assessment of GH is unreliable because of the pulsatile release of these hormones that result in pronounced serum fluctuations within 24-h period [3,71]. Insulin-like growth factor-1 (IGF-1) is often used as a surrogate marker of GH levels [18,32] however, 50\% of adults with GHD have IGF-1 levels within the normal reference range [72]. Similarly, patients with a normal GH response can have low IGF-1 levels $[18,64]$.

Peak GH secretion during provocative testing is used to assess the capacity of the pituitary to release GH [73]. The ITT is considered the "gold standard" in provocative tests for diagnosing GHD [18,74,75]; however, it cannot be safely performed in patients with seizures or severe cardiovascular disease [76,77]. This contraindication limits its use in patients with TBI. The glucagon stimulation test (GST) has comparable diagnostic accuracy and reliability as the ITT $[32,78,79]$ and is well tolerated in patients with TBI. A single provocative test is sufficient for the diagnosis of GHD in adults [80]. It should be noted that basal hormone assessments and the results of provocative tests need to be interpreted within the context of the patient's medical 
history, clinical exam, and symptoms.

\section{Treatment of neuroendocrine dysfunction}

Given the significant overlap of symptoms between TBI and hormonal deficiencies, it follows that debilitating symptoms associated with neuroendocrine deficiency may be alleviated by hormonal replacement. As a result, patients with TBI and treated neuroendocrine deficiencies may be able to improve their rehabilitation outcome at a faster rate than those patients with TBI that did not receive hormone replacement. For some hormones, such as cortisol, symptoms of pituitary dysfunction can be life threatening and require hydrocortisone therapy immediately [40]. Once cortisol levels are within the normal range, replacement of other hormones, such as thyroid hormone, can be initiated [40]. Cognitive improvements, specifically in the area of verbal memory retrieval have been demonstrated with thyroid replacement [81]. Sexual function, libido, muscle, and bone formation improvements have been reported with testosterone replacement in men $[82,83]$. Improvements in cognitive functioning have been reported in women who have undergone estrogen replacement [46,47]. After GHD has been diagnosed, GH replacement is warranted. Most of the literature on hormone replacement following TBI focuses on GH replacement. GH replacement in adults without TBI has been shown to improve body composition through decreased waist circumference [55], increased muscle mass [84], improved metabolic profiles [55], and improved cardiac function [85]. Additionally, GH replacement has been shown to improve cognitive, psychiatric and physical functioning post-TBI [86-90]. Specifically, GH replacement was shown to improve tasks that assessed verbal learning, information processing speed, executive functions, and motor dexterity and speed for the dominant hand compared to the control group [87]. Similarly, Moreau and colleagues. found modest improvements for those patients replaced with GH on tasks that assess verbal memory, nonverbal memory, confrontation naming, and executive functions, but not on a test of cognitive flexibility [90]. In another study, Reimunde et al. assessed the impact of GH treatment in patients with moderate to severe TBI following 3 months of GH replacement [88]. Improvements were noted on tests of crystallized skills including vocabulary, Verbal Intelligence Quotient, and Full Scale Intelligence Quotient on the Wechsler Intelligence Scale. It should be noted that hormone replacement should be prescribed and monitored by an endocrinologist.

Neuroendocrine dysfunction following TBI is a significant issue that may impede recovery. Due to overlapping symptoms between TBI and hormone deficiencies, assessment of the neuroendocrine system may not be undertaken. Hormone replacement may improve cognitive, physical and psychosocial symptoms and may allow for more complete recovery following TBI.

\section{Sleep and TBI}

\section{Impact of TBI on sleep}

Sleep is known to be an essential component of daily living; critical for optimal cognitive processing, immune system functioning, emotional balance and general health. Disturbances in sleep have been linked to impaired attention, diminished executive functioning, and poor memory consolidation, as well as increases in emotional/ behavioral difficulties and maladaptive changes in SNS/HPA activation and inflammatory responses $[2,46,91,92]$.

Sleep-wake disturbances (SWDs), including such disorders as insomnia and hypersomnia, excessive daytime sleepiness, REM sleep behavior disorder and sleep-disordered breathing (SDB), etc., have been identified in up to $\sim 80 \%$ of brain injured patients; rates that are much higher than the general population [93]. Sleep disturbances may appear in the acute or post-acute phase, generally continue to worsen after brain injury $[94,95]$ and may persist on a chronic timeline [96-100]. SWD may be a primary result of damage to the sleep-wake regulatory systems in the brain, or a product of secondary consequences of the injury such as depression, pain, anxiety, and pharmacologic treatments [95]. To our knowledge, no studies to date have been able to causally link damage to specific sleep-wake circuitry from TBI to post-injury SWDs. However many studies have shown correlations between abnormalities in the sleep-wake regulatory systems, and subjective and objective measures of SWD in brain injury patients and rodent models of TBI (referenced below).

A number of studies have identified hypothalamic abnormalities in patients with brain injury, more specifically, to the wake promoting hypocretin/orexin neurons concentrated within the hypothalamus $[96,101,102]$. The aforementioned studies have shown a decreased amount of hypocretin containing neurons in TBI patients, a decrease that persisted in some patients 6 months postinjury [101]. Additionally, patients with TBI and excessive daytime sleepiness have exhibited cortical hypoexcitability [103]. Decreased CSF levels of hypocretin may contribute to the hypoexcitability by reducing the amount of inhibition on GABAergic cells in the neocortex [103]. Involvement of the hypothalamus is especially pertinent due to its control over the pituitary gland, and speaks to the reciprocal nature of the sleep-wake and endocrine systems. In addition to hypothalamic disturbances, TBI patients show decreased levels of evening melatonin, a hormone that helps regulate sleepwake cycles [104]. Studies using animal models of TBI show similar findings, which support the role of hypothalamic dysregulation in disturbed sleep post-trauma. TBI in rodent models causes cognitive impairment and depressive-like symptoms at least 30 days following liquid fluid percussion induced injury [105]. These symptoms were also accompanied by a reduction in orexin producing neurons in the lateral hypothalamus [105]. Similar reductions in the hypocretin and cholinergic systems have been found using controlled cortical impact models, with corresponding disruptions in the normal sleep-wake cycle [106,107].

In addition to the objective disturbances in the sleep-wake regulatory systems, clinical observations have shown an increased amount of sleep immediately following brain injury (acute posttraumatic sleep). Rodent models are now beginning to investigate the mechanism and function of this phenomenon, as mice and rats with TBI also display increases in sleep post-injury $[105,106,108,109]$. Secondary restorative mechanisms that are initiated post-injury may promote sleep by increasing inflammation through elevated levels of cytokines, which also promote sleep, and increasing levels of reactive oxygen species (ROS) in the brain. These secondary cellular processes have been hypothesized to induce post-traumatic sleep and, as they continue, may contribute to chronic SWD [108]. In rodent models, 
however, while increases in sleep time have been recorded into the first week post-injury, the disturbances did not develop into chronic issues [110]. This contradicts the chronic nature of sleep disturbances seen in TBI patients; further investigation is warranted.

Studies utilizing polysomnography have indicated decreases in REM sleep and sleep efficiency, and increases in sleep latency, wake after sleep onset (WASO) and slow-wave sleep, as compared to the general population $[104,109,111,112]$. Increases in slowwave sleep have also been identified following mild TBI in rodents [109]. Slow-wave sleep characteristics in TBI may be affected by lesions in the basal forebrain, as lesions in that region have been shown to produce electroencephalogram (EEG) slow-waves and coma $[113,114]$. It should be noted that, in spite of the utilization of objective polysomnography, some inconsistencies between groups do exist; such discrepancies are likely to be influenced by differences in experimental design and patient heterogeneity.

A number of influencing factors such as depression/anxiety, chronicity, injury severity, and aging should be considered when addressing SWD after TBI. TBI patients report significantly higher levels of subjective depression and anxiety, as well as poorer sleep quality than controls $[95,104,111,112,115]$. The increased levels of depression and anxiety are likely to contribute to SWDs, as similar subjective and objective sleep disturbances are common in patients with depression and no reported history of brain injury [116]. Compounding the depression/anxiety/sleep disturbance conundrum is the factor of pharmacological treatment post-injury, as many drugs commonly prescribed to brain injury patients can cause excessive sleepiness, insomnia, depression and/or anxiety. These factors considered together have a significant effect on reduction in quality of life for these patients $[100,117,118$,$] .$

Additional variables to consider when addressing SWD after TBI are injury chronicity and injury severity. As mentioned above, SWDs may appear at any point in the recovery continuum; the primary issue is to continue to monitor for these disturbances during the rehabilitative process. Fatigue and post-traumatic hypersomnia have been observed 3-years post-trauma [98]. Although SWDs have been identified in a wide range of injury severities, some samples have identified a worsening of sleep-related complaints and longer sleeptime requirements as injury severity increased [118].

Age is also a critical variable that should be considered when addressing SWDs after TBI, as aging has a profound impact on all aspects of sleep, and correlates with increases in SWDs [119]. Given the effects of age on sleep, it is likely that aging will contribute to, or exacerbate TBI associated SWD; thus, early identification and treatment of SWDs may prevent chronic sleep alterations and/or alleviate age related SWDs. Other important variables to consider are body mass index (BMI) and the patient's sex. These variables, along with age, can provide valuable information on the likelihood of SWD, particularly SDB as increased BMI and the male gender have shown a positive correlation with the presence of SDB [120-122]; however, SDB may be under diagnosed in women due to the possibility of differing symptoms [122].

\section{SWDs impact rehabilitation}

Recent research has attempted to highlight the association between TBI and SWD; however, it is a sequelae that remains largely under recognized in clinical settings [123]. For TBI patients, whose cognitive and affective processes are already affected as a result of their injuries, these impairments are particularly concerning and can ultimately decrease the likelihood of a positive rehabilitative outcome.

Disruptions in the normal sleep-wake cycle have been found to negatively impact rehabilitation by increasing negative behavior, decreasing concentration, and increasing the likelihood that patients would stay in bed during sessions [124]. Cognitively, TBI patients show deficits in executive functions including attention, verbal fluency, creativity and planning skills, etc., that may be moderated by secondary variables such as SWD, fatigue and depression [125128]. Further, the frontoparietal regions of the brain that control these functions are particularly vulnerable to injury via diffuse axonal injury and focal cortical contusions; the networks in these areas are also disproportionately affected by disruptions in sleep [125,128]. Sleep has also been identified as a requirement for the consolidation of hippocampal dependent memory consolidation, as well as motorskill learning [5,129-131]. Disturbances in sleep for TBI patients can thus interfere with progress that may otherwise be made in these areas during the rehabilitative process. In addition to deficits in rehabilitation performance and cognitive difficulties, SWD have been linked to longer rehabilitative stays [132]. All of these considered together will ultimately affect the ability of patients to reach their full rehabilitative/outcome potential.

\section{SWD within the rehabilitative setting}

Knowing the potential consequences of SWDs and the correlation with brain injury, a concerted effort should be made to properly screen, diagnose, and treat these disturbances in the rehabilitative setting in order to improve patient outcome [134]. Screening may include a combination of clinical interviews, sleep diaries, and selfreported questionnaires. This type of self-reported screening may assist with early identification of SWDs in order to combat any age associated changes for TBI patients. During the clinical interview, one can establish important baseline information by documenting pre- and current sleep patterns, comorbid factors that may contribute to SWD (pain, anxiety, depression, etc.), use of prescription and nonprescription medications, use of illicit drugs, and core symptoms of SWD (i.e. snoring, nightmares, limb movements, etc.). In addition to clinical interviews, sleep diaries may be useful for self-monitoring the nature, frequency, and severity of any disturbances in sleep. A number of subjective questionnaires may also be administered, including the commonly used Epworth Sleepiness Scale and the Pittsburgh Sleep Quality Index [135]. Objective measures of SWD, such as the polysomnography, should be used whenever possible, as this measure gives the most accurate depiction of brain, muscle and respiratory activity. Actigraphy may also be used as a more feasible measure, allowing for a relatively simple, non-invasive way to assess sleep-wake cycles over extended periods of time; however, the reliability and accuracy of actigraphy has not yet been fully validated, especially in regards to brain injury [136].

Once any SWDs are identified, the issue then, becomes how to treat the disturbance in the most beneficial, but feasible way. Treatment for SWD's is multifaceted and depends largely on the type of disturbance. Utilizing a combination of the above mentioned 
screening/diagnostic techniques can aid in better identification of the root-cause of the disturbance, and thus, more appropriate treatment. Common treatment for SDB includes the use of continuous positive airway pressure (CPAP) or bi-level positive airway pressure (BiPAP) machines, which treat apnea by increasing air pressure in the throat in order to keep the airway from collapsing while a person sleeps. Pharmacologically, many options exist: dopamine agonists may be used to treat restless leg syndrome or periodic limb movement disorder; benzodiazepines, anticonvulsants or orexin receptor antagonists for insomnia; stimulants for hypersomnia, etc. There is overlap with these medications, some of which are also used to treat depression and anxiety. Ideally, medications should be used shortterm and ought to be paired with good sleep hygiene and other behavioral treatments (i.e. relaxation training, cognitive therapy, etc.). Sleep hygiene is an intervention that can be implemented in the rehabilitative setting. Some examples of effective strategies may include behavioral modifications such as limiting day time naps, promoting aerobic exercise and exposure to natural light when possible, as well as avoiding stimulants close to bedtime (caffeine, nicotine, etc.).

In the rehabilitative setting, other interventions that may be utilized include forms of light therapy and counseling. Exposure to forms of light, red light and near infrared light therapy have been shown to reduce sleepiness and improve mood in healthy adult populations and may also prove useful for patients with TBI [137139]. Counseling may provide a beneficial support system for patients with TBI who are experiencing disruptions in sleep, especially if depression/anxiety is thought to be the basis of the SWD. Keep in mind that proper treatment may, and often does, require a mixture of treatment paradigms. Regardless of the chosen intervention, feasibility may be limited when dealing with the brain-injured population. Adherence to CPAP use, medications, light therapy etc. should be closely monitored.

\section{Interplay between Neuroendocrine Function and Sleep}

The hypothalamus is a key regulator of both the neuroendocrine system and sleep-wake cycles. The hypothalamus controls the release of hormones from the pituitary gland as well as hypocretin/orexin release to promote wakefulness. Many hormones, such as growth hormone and cortisol, are released during specific stages of sleep, therefore, disruptions in sleep can negatively affect hormone release. In fact, hormone release is frequently decreased in individuals with sleep disorders such as obstructive sleep apnea [140-142]. Additionally, issues such as increased abdominal adiposity and BMI are present in both patients who have hormone deficiencies and sleep apnea. Similarly, emotional dysregulation, in the forms of depression and anxiety, are also clearly influenced by hormones and sleep. It is evident that alterations in one of these systems will ultimately have an impact on the other. These examples illustrate the bidirectional interplay between sleep and hormones and further the notion that it is important to evaluate sleep and neuroendocrine functioning together during the post-acute rehabilitation period.

\section{Conclusion}

Neuroendocrine and sleep disorders have not always been appropriately considered and addressed in the context of rehabilitation, possibly to the detriment of patients. Both sleep and neuroendocrine disorders can have long lasting, but sometimes subtle effects on recovery, patient outcomes and ultimately quality of life. With limited interventions available following TBI, these two areas seem to represent fertile territories for further investigation and intervention.

\section{References}

1. Dams-O'Connor, K, Spielman, L, Singh, A, Gordon, WA, Lingsma, HF Maas, Al, et al. The Impact of Previous Traumatic Brain Injury on Health and Functioning: A TRACK-TBI Study. J. Neurotrauma. 2013; 30: 2014-2020.

2. Fulda S, \& Shulz H. Cognitive Dysfunction in Sleep Disorders. Sleep Medicine Reviews. 2001; 5: 423-445.

3. Lieberman SA, Oberoi AL, Gilkison CR, Masel BE, Urban RJ. Prevalence of Neuroendocrine Dysfunction in Patients Recovering from Traumatic Brain Injury. J Clin Endocrinol Metab. 2001; 86: 2752-2756.

4. Nilsson JP, Soderstrom M, Karlsson AU, Lekander M, Akerstedt T, Erixon Lindroth $\mathrm{N}$, et al. Less Effective Executive Functioning After One Night's Sleep Deprivation. Journal of Sleep Research. 2005; 14: 1-6.

5. Diekellman S, Born J. The Memory Function of Sleep. Nature Reviews. 2010; 11: 114-126

6. Marshall L, Born J. The Contribution of Sleep to Hippocampus-Dependent Memory Consolidation. Trends in Cognitive Sciences. 2007; 11: 442-450.

7. Benvenga S, Campenni A, Ruggeri RM, Trimarchi F. Clinical Review 113: Hypopituitarism Secondary to Head Trauma. J Clin Endocrinol Metab. 2000; 85: 1353-1361.

8. Edwards OM, Clark JD. Post-Traumatic Hypopituitarism. Six cases and a Review of the Literature. Medicine. 1986; 65: 281-290.

9. Agha A, Rogers B, Sherlock M, O'Kelly P, Tormey W, Phillips J, and Thompson CJ. Anterior Pituitary Dysfunction in Survivors of Traumatic Brain Injury. J. Clin. Endocrinol. Metab. 2004; 89: 4929-4936.

10. Kelly DF, Gonzalo IT, Cohan P, Berman N, Swerdloff R, Wang C. Hypopituitarism Following Traumatic Brain Injury and Aneurysmal Subarachnoid Hemorrhage: A Preliminary Report. J Neurosurg. 2000; 93: 743-752.

11. Bondanelli M, De Marinis L, Ambrosio MR, Monesi M, Valle D, Zatelli MC, et al. Occurrence of Pituitary Dysfunction Following Traumatic Brain Injury. J Neurotrauma. 2004; 21: 685-696.

12. Aimaretti G, Ambrosio MR, Di Somma C, Gasperi M, Cannavo S, Scaroni C, et al. Residual Pituitary Function After Brain Injury-Induced Hypopituitarism: A Prospective 12-month study. J Clin Endocrinol Metab. 2005; 90: 60856092.

13. Agha A \& Thompson CJ. Anterior Pituitary Dysfunction Following Traumatic Brain Injury. Clin Endocrinol. 2006; 64: 481-488.

14. Nemes O, Kovacs N, Czeiter E, Kenyeres P, Tarjanyi Z, Bajnok L, et al. Predictors of Post-Traumatic Pituitary Failure During Long-term Follow-Up. Hormones. 2015; 14: 383-391.

15. Nemes O, Kovacs N, Szujo S, Bodis B, Bajnok L, Buki A, et al. Can Early Clinical Parameters Predict Post-Traumatic Pituitary Dysfunction in Severe Traumatic Brain Injury? Acta Neurochir. 2016; 158: 2347-2353.

16. Gupta AK, Zygun DA, Johnston AJ, Steiner LA, Al-Rawi PG, Chatfield D, et al. Extracellular Brain $\mathrm{pH}$ and Outcome Following Severe Traumatic Brain Injury. J Neurotrauma. 2004; 21: 678-684.

17. Harper CG, Doyle D, Adams JH \& Graham DI. Analysis of Abnormalities in Pituitary Gland in Non-Missle Head Injury: Study of 100 Consecutive Cases. J Clin Pathol. 1986; 39: 769-773.

18. Ghigo E, Masel B, Aimaretti G, Leon-Carrion J, Casanueva FF, DominguezMorales MR, et al. Consensus Guidelines on Screening for Hypopituitarism Following Traumatic Brain Injury. Brain Inj. 2005; 19: 711-724. 
19. Klose M, Juul A, Poulsgaard L. Prevalence and Predictive Factors of PostTraumatic Hypopituitarism. Clin Enocrinol. 2007; 67: 193-201.

20. Popovic V, Pekic S, Pavlovic D, Maric N, Jasovic-Gasic M, Djurovic B, et al. Hypopituitarism as a Consequence of Traumatic Brain Injury (TBI) and Its Possible Relation with Cognitive Disabilities and Mental Distress. J Endocrinol Invest. 2004; 27: 1048-1054.

21. Rothman MS, Arciniegas DB, Filley CM, \& Wierman ME. The Neuroendocrine Effects of Traumatic Brain Injury. J Neuropsychiatry Clin Neurosci. 2007; 19 363-372.

22. Thompson C. Traumatic Brain Injury-Induced Hypopituitarism: Whom and When to Test. Endocrine Abstracts. 2007; 14: S1.1.

23. Hannon MJ, Sherlock M, Thompson CJ. Pituitary Dysfunction Following Traumatic Brain Injury or Subarachnoid Haemorrhage - in "Endocrine Management in the Intensive Care Unit". Best Pract Res Clin Endocrino Metab. 2011; 25: 783-798.

24. Masel BE, Urban R. Chronic Endocrinopathies in Traumatic Brain Injury Disease. J Neurotrauma. 2015; 32: 1902-1910.

25. Tritos NA, Yuen K, Kelly DF. American Association of Clinical Endocrinologists and American College of Endocrinology Disease State Clinical Review: A neuroendocrine approach to patients with traumatic brain injury. Endocr Pract. 2015; 21: 823-831.

26. Agha A, Rogers B, Sherlock M, O'Kelly P, Tormey W, Phillips J, et al Anterior Pituitary Dysfunction in Survivors of Traumatic Brain Injury. J Clin Endocrinol Metab. 2004; 89: 4929-4936.

27. Agha A, Thompson CJ. High Risk of Hypogonadism After Traumatic Brain Injury: Clinical Implications. Pituitary. 2005; 8: 245-249.

28. Schneider HJ, Schneider $M$, Kreitschmann-Andermahr I, Tuschy $U$ Wallaschofski H, Fleck S, et al. Structured Assessment of Hypopituitarism After Traumatic Brain Injury and Aneurysmal Subarachnoid Hemorrhage in 1242 patients: The German Interdisciplinary Database. J Neurotrauma 2011; 28: 1693-1698.

29. Tanriverdi $F$, Ulutabanca $H$, Unluhizarci $K$, Selcuklu A, Casanueva FF, Kelestimur F. Three Years Prospective Investigation of Anterior Pituitary Function After Traumatic Brain Injury: A Pilot Study. Clin. Endocrinol. 2008; 68: 573-579.

30. Krahulik D, Zapletalova J, Frysak Z, Vaverka M. Dysfunction of HypothalamicHypophysial Axis After Traumatic Brain Injury in Adults. J Neurosurg. 2010; 113: $581-584$

31. Wilkinson CW, Pagulayan KF, Petrie EC, Mayer CL, Colasurdo EA Shofer JB, et al. High Prevalence of Chronic and Target-Organ Hormone Abnormalities After Blast-Related Mild Traumatic Brain Injury. Frontiers in Neurology. 2012; 3: 1-12.

32. Ho KK. GH Deficiency Consensus Workshop Participants. Consensus Guidelines for the Diagnosis and Treatment of Adults with GH Deficiency II: A Statement of the GH Research Society in Association with the European Society for Pediatric Endocrinology, Lawson Wilkins Society, European Society of Endocrinology, Japan Endocrine Society, and Endocrine Society of Australia. Eur. J. Endocrinol. 2007; 157: 695-700.

33. Behan LA, Phillips J, Thompson CJ, Agha A. Neuroendocrine Disorders After Traumatic Brain Injury. J Neurol Neurosurg Psychiatry. 2008; 79: 753 759.

34. Bondanelli M, Ambrosio MR, Cavazzini L, Bertocchi A, Zatelli MC, Carli A, et al. Anterior Pituitary Function May Predict Functional and Cognitive Outcome in Patients with Traumatic Brain Injury Undergoing Rehabilitation. J Neurotrauma. 2007; 24: 1687-1697.

35. Cohan P, Wang C, McArthur DL, Cook SW, Dusick JR, Armin B, et al. Acute Secondary Adrenal Insufficiency After Traumatic Brain Injury: A Prospective Study. Crit Care Med. 2005; 33: 2358-2366.

36. Klose M, Feldt-Rasmussen U. Does the Type and Severity of Brain Injury Predict Hypothalamo-Pituitary Dysfunction? Does Post-Traumatic Hypopituitarism Predict Worse Outcome? Pituitary. 2008; 11: 255-261.
37. Masel BE \& DeWitt DS. Traumatic Brain Injury: A Disease Process, Not an Event. J Neurotrauma. 2010; 27: 1529-1540.

38. Cuneo RC, Salomon F, McGauley GA, Sonksen PH. The Growth Hormone Deficiency Syndrome in Adults. Clin Endocrinol. 1991; 37: 387-397.

39. Schneider HJ, Kreitschmann-Andermahr I, Ghigo E, Stalla GK, Agha A Hypothalamopituitary Dysfunction Following Traumatic Brain Injury and Aneurysmal Subarachnoid Hemorrhage: A Systematic Review. JAMA. 2007; 298: $1429-1438$

40. Urban RJ, Harris P, Masel B. Anterior Hypopituitarism Following Traumatic Brain Injury. Brain Inj. 2005; 19: 349-358.

41. Rodrigues MA, Verdile G, Foster JK, Hogervorst E, Joesbury K, Dhaliwal S, et al. Gonadotropins and Cognition in Older Women. Journal of Alzheimer's Disease. 2008; 13: 267-274.

42. Webber KM, Perry G, Smith MA, Casadesus G. The Contribution of Luteinizing Hormone to Alzheimer Disease Pathogenesis. Journal of Clinical Medicine Research. 2007; 5: 177-183.

43. Aleman A, De Vries WR, Koppeschaar HP, Osman-Dualeh M, Verhaar HJ, Samson MM, Bol E, et al. Relationship Between Circulating Levels of Sex Hormones and Insulin-Like Growth Factor-1 and Fluid Intelligence in Older Men. Experimental Aging Research. 2001; 27: 283-291.

44. Boss L, Kang D, Marcus M, Bergstrom N. Endogenous Sex Hormones and Cognitive Function in Older Adults: A Systematic Review. Western Journal of Nursing Research. 2013; 36: 388-426.

45. Muller M, Aleman A, Grobbee, DE, de Haan EH and van der Schouw YT Endogenous Sex Hormone Levels and Cognitive Functioning in Aging Men: Is There an Optimal Level? Neurology. 2005; 64: 866-871.

46. Costa MM, Reus VI, Wolkowitz OM, Manfredi F, Lieberman M. Estrogen Replacement Therapy and Cognitive Decline in Memory-Impaired PostMenopausal Women. Biol Psychiatry. 1999; 46: 182-188.

47. Jacobs DM, Tang MX, Stern Y, Sano M, Marder K, Bell KL, et al. Cognitive Function in Nondemented Older Women Who Took Estrogen After Menopause. Neurology. 1998; 50: 368-373.

48. Denicoff KD, Joffe RT, Lakshmanan MC, Robbins J and Rubinow DR. Neuropsychiatric Manifestations of Altered Thyroid State. Am. J. Psychiatry. 1990; 147: 94-99.

49. Davis, JD, Tremont, G. Neuropsychiatric Aspects of Hypothyroidism and Treatment Reversibility. Minerva Endocrinol. 2007; 32: 49-65.

50. Carroll PV, Christ ER, Bengtsson BA, Carlsson L, Christiansen JS, Clemmons D, et al. Growth Hormone Deficiency in Adulthood and the Effects of Growth Hormone Replacement: A Review. Growth Hormone Research Society Scientific Committee. J Clin Endocrinol Metab. 1998; 83: 382-395.

51. Hohl A, Ronsoni M, Sande-Lee S, Vieira F, Schwarzbold M, Diaz A, et al. Androgens, Male Hypogonadism and Traumatic Brain Injury. J Endocr Metab Dis. 2014; 4: 13-23.

52. Tomlinson JW, Holden N, Hills RK, Wheatley K, Clayton RN, Bates AS, et al. Association Between Premature Mortality and Hypopituitarism. West Midlands Prospective Hypopituitary Study Group. Lancet. 2001; 357: 425431.

53. Binnerts A, Deurenberg P, Swart GR, Wilson JH, Lamberts SW. Body Composition in Growth Hormone-Deficient Adults. Am J Clin Nutr. 1992; 55: 918-923.

54. Colao A, Di Somma C, Pivonello R, Loche S, Aimaretti G, Cerbone G, et al. Bone Loss is Correlated to the Severity of Growth Hormone Deficiency in Adult Patients with Hypopituitarism. J Clin Endocrinol Metab. 1999; 84: 1919-1924.

55. Crespo I, Santos A, Webb SM. Quality of Life in Patients with Hypopituitarism. Curr Opin Endocrinol Diabetes Obes. 2015; 22: 306-312.

56. Merola B, Cittadini A, Colao A, Longobardi S, Fazio S, Sabatini D, et al. Cardiac Structural and Functional Abnormalities in Adult Patients with Growth Hormone Deficiency. J Clin Endocrinol Metab. 1993; 77: 1658-1661. 
57. Beshyah SA, Johnston DG. Cardiovascular Disease and Risk Factors in Adults with Hypopituitarism. Clin Endocrinol. 1999; 50: 1-15.

58. Rosen T, Bengtsson BA. Premature Mortality Due to Cardiovascular Disease in Hypopituitarism. Lancet. 1990; 336: 285-288.

59. Agha A, Phillips J, Thompson CJ. Hypopituitarism Following Traumatic Brain Injury (TBI). British Journal of Neurosurgery. 2007; 21: 210-216.

60. Bjork S, Jonsson B, Westphal O, Levin JE. Quality of Life of Adults with Growth Hormone Deficiency: A Controlled Study. Acta Paediatr Scand Suppl. 1989; 356: 55-59; discussion 60, 73-74.

61. Fleminger S. Long-Term Psychiatric Disorders After Traumatic Brain Injury. Eur J Anaesthesiol Suppl. 2008; 42: 123-130.

62. Reeves RR, Panguluri RL. Neuropsychiatric Complications of Traumatic Brain Injury. J Psychosoc Nurs Ment Health Serv. 2011; 49: 42-50.

63. Zgaljardic D, Schaefer L. Neurology and Neuropsychology. In: Hunter C Kessler R, Hunter C, editors. Handbook of Clinical Psychology in Medical Settings: Evidence-Based Assessment and Intervention. Springer-Verlag Publications. 2014.

64. Kreber LA, Griesbach GS, Ashley MJ. Detection of Growth Hormone Deficiency in Adults with Chronic Traumatic Brain Injury. J Neurotrauma. 2016; 33: 1607-1613.

65. Castanho TC, Moreira PS, Portugal-Nunes C, Novais A, Soares Costa P, Almeida Palha, J, et al. The Role of Sex and Sex-related Hormones in Cognition, Mood and Well-Being in Older Men and Women. Biological Psychology. 2014; 103: 158-166.

66. Seel RT, Kreutzer JS. Depression Assessment After Traumatic Brain Injury: An Empirically Based Classification Method. Arch Phys Med Rehabil. 2003 84: $1621-1628$.

67. Urban RJ. Hypopituitarism After Acute Brain Injury. Growth Horm IGF Res. 2006; 16: 25-29

68. Fernandez-Rodriguez E, Bernabeu I, Castro Al, Kelestimur F, Casanueva FF. Hypopituitarism Following Traumatic Brain Injury: Determining Factors for Diagnosis. Frontiers in Endocrinology. 2011; 2: 25.

69. Herrmann BL, Rehder J, Kahlke S, Wiedemayer H, Doerfler A, Ischebeck W, et al. Hypopituitarism Following Severe Traumatic Brain Injury. Exp Clin Endocrinol Diabetes. 2006; 114: 316-321.

70. Toogood, AA \& Stewart, PM. Hypopituitarism: Clinical Features, Diagnosis and Management (Review). Endocrinology and Metabolism Clinics of North America. 2008; 37: 235-261.

71. Rosario ER, Aqeel R, Brown MA, Sanchez G, Moore C and Patterson D. Hypothalamic-Pituitary Dysfunction Following Traumatic Brain Injury Affects Functional Improvement During Acute Inpatient Rehabilitation. J. Head Trauma Rehabil. 2013; 28: 390-396.

72. Lissett CA, Jonsson P, Monson JP, Shalet SM, Board KI. Determinants of IGF-I Status in a Large Cohort of Growth Hormone-Deficient (GHD) Subjects: The Role of Timing of Onset of GHD. Clin Endocrinol. 2003; 59: 773-778.

73. Zgaljardic DJ, Guttikonda S, Grady JJ, Gilkison CR, Mossberg KA, High WM $\mathrm{Jr}$, et al. Serum IGF-1 Concentrations in a Sample of Patients with Traumatic Brain Injury as a Diagnostic Marker of Growth Hormone Secretory Response to Glucagon Stimulation Testing. Clin Endocrinol. 2011; 74: 365-369.

74. Casanueva FF, Castro Al, Micic D, Kelestimur F, Dieguez C. New Guidelines for the Diagnosis of Growth Hormone Deficiency in Adults. Horm Res. 2009; 71: 112-115.

75. Biller BM, Samuels MH, Zagar A, Cook DM, Arafah BM, Bonert V, et al. Sensitivity and Specificity of Six Tests for the Diagnosis of Adult GH Deficiency. J Clin Endocrinol Metab. 2002; 87: 2067-2079.

76. Jones SL, Trainer PJ, Perry L, Wass JA, Bessser GM, Grossman A. An Audit of the Insulin Tolerance Test in Adult Subjects in an Acute Investigation Unit Over One Year. Clin Endocrinol. 1994; 41: 123-128.

77. Yuen KC, Biller BM, Molitch ME, Cook DM. Clinical Review: Is Lack of Recombinant Growth Hormone $(\mathrm{GH})$-Releasing Hormone in the United
States a Setback or Time to Consider Glucagon Testing for Adult GH Deficiency? J Clin Endocrinol Metab. 2009; 94: 2702-2707.

78. Conceicao FL, da Costa e Silva A, Leal Costa AJ, Vaisman M. Glucagon Stimulation Test for the Diagnosis of GH Deficiency in Adults. J Endocrinol Invest. 2003; 26: 1065-1070.

79. Gomez JM, Espadero RM, Escobar-Jimenez F, Hawkins F, Pico A, HerreraPombo JL, et al. Growth Hormone Release After Glucagon as a Reliable Test of Growth Hormone Assessment in Adults. Clin Endocrinol. 2002; 56: 329-334.

80. Gabellieri E, Chiovato L, Lage M, Castro Al, Casanueva FF. Testing Growth Hormone Deficiency in Adults. Front Horm Res. 2010; 38: 139-144.

81. Miller KJ, Parsons TD, Whybrow PC, van Herle K, Rasgon N, van Herele A, et al. Memory Improvement with Treatment of Hypothyroidism. Int J Neurosci. 2006; 116: 895-906.

82. Wang C, Eyre DR, Clark R, Kleinberg D, Newman C, Iranmanesh A, et al. Sublingual Testosterone Replacement Improves Muscle Mass and Strength, Decreases Bone Resorption, and Increases Bone Formation Markers in Hypogonadal Men--A Clinical Research Center Study. J Clin Endocrinol Metab. 1996; 81: 3654-3662.

83. Swerdloff RS, Wang C. Androgen Deficiency and Aging in Men. West J Med. 1993; 159: 579-585.

84. Johannsson G, Grimby G, Sunnerhagen KS, Bengtsson BA. Two Years of Growth Hormone $(\mathrm{GH})$ Treatment Increase Isometric and Isokinetic Muscle Strength in GH-Deficient Adults. J Clin Endocrinol Metab. 1997; 82: 2877 2884 .

85. Nass R, Huber RM, Klauss V, Muller OA, Schopohl J, Strasburger CJ. Effect of Growth Hormone (hGH) Replacement Therapy on Physical Work Capacity and Cardiac and Pulmonary Function in Patients with hGH Deficiency Acquired in Adulthood. J Clin Endocrinol Metab. 1995; 80: 552-557.

86. Maric NP, Doknic M, Pavlovic D, Pekic S, Stojanovic M, Jasovic-Gasic M, et al. Psychiatric and Neuropsychological Changes in Growth HormoneDeficient Patients After Traumatic Brain Injury in Response to Growth Hormone Therapy. J Endocrinol Invest. 2010; 33: 770-775

87. High WM Jr, Briones-Galang M, Clark JA, Gilkison C, Mossberg KA, Zgaljardic DJ, et al. Effect of Growth Hormone Replacement Therapy on Cognition After Traumatic Brain Injury. J Neurotrauma. 2010; 27: 1565-1575.

88. Reimunde P, Quintana A, Castanon B, Casteleiro N, Vilarnovo Z, Otero A, et al. Effects of Growth Hormone (GH) Replacement and Cognitive Rehabilitation in Patients with Cognitive Disorders after Traumatic Brain Injury. Brain Inj. 2011; 25: 65-73.

89. Devesa J, Reimunde P, Devesa P, Barbera M, Arce V. Growth Hormone (GH) and Brain Trauma. Horm Behav. 2013; 63: 331-344.

90. Moreau OK, Cortet-Rudelli C, Yollin E, Merlen E, Daveluy W, Rousseaux M. Growth Hormone Replacement Therapy in Patients with Traumatic Brain Injury. J Neurotrauma. 2013; 30: 998-1006.

91. Motivala SJ. Sleep and Inflammation: Psychoneuroimmunology in the Context of Cardiovascular Disease. Annals of Behavioral Medicine. 2011; 42: 141-152.

92. Lange T, Dimitrov S, Born J. Effects of sleep and Circadian Rhythm on the Human Immune System. Annals of the New York Academy of Sciences. 2010; 1193: 48-59

93. Mathias JL, Alvaro PK. Prevalence of Sleep Disturbances, Disorders, and Problems After Traumatic Brain Injury: A Meta-Analysis. Sleep Medicine. 2012; 13: 898-905

94. Gardani M, Morfiri E, Thomson A, O'Neil B, McMillan TM. Evaluation of Sleep Disorders in Patients with Severe Traumatic Brain Injury During Rehabilitation. Archives of Physical Medicine and Rehabilitation. 2015; 96: 1691-1697.

95. Ouellet MC, Beaulieu-Bonneau S, Morin CM. Sleep-Wake Disturbances After Traumatic Brain Injury. Lancet Neurology. 2015; 14: 746-757.

96. Baumann CR, Werth E, Stocker R, Ludwig S, Bassetti CL. Sleep-Wake 
Disturbances 6 Months After Traumatic Brain Injury: A Prospective Study. Brain. 2007; 130: 1873-1883.

97. Verma A, Anand V, \& Verma NP. Sleep Disorders in Chronic Traumatic Brain Injury. Journal of Clinical Sleep Medicine. 2007; 3: 357-362.

98. Kempf J, Werth E, Kaiser PR, Bassetti CL, \& Baumann, C.R. Sleep-wake disturbances 3 years after traumatic brain injury. Journal of Neurology Neurosurgery and Psychiatry. 2010; 81: 1402-1405.

99. Imbach LL, Bucjele F, Valko PO, Li T, Maric A, Stover JF, et al. SleepWake Disorders Persist 18 Months After Traumatic Brain Injury but Remain Underrecognized. Neurology. 2016; 86: 1945-1949.

100. Chen PY, Tsai PS, Chen, NH, Chaung, LP, Lee, CC, Chen CC, et al Trajectories of Sleep and its Predictors in the First Year Following Traumatic Brain Injury. Journal of Head Trauma Rehabilitation. 2015; 30: 50-55.

101. Baumann CR, Stocker R, Imhof HG, Trentz O, Hersberger M, Mignot E, et al. Hypocretin-1 (Orexin A) Deficiency in Acute Traumatic Brain Injury. Neurology. 2005; 65: 147-149.

102. Baumann CR, Bassetti CL, Valko PO, Haybaeck J, Keller M, Clark E, et al Loss of Hypocretin (Orexin) Neurons with Traumatic Brain Injury. Annals of Neurology. 2010; 66: 555-559.

103. Nardone R, Bergmann J, Kunz A, Caleri F, Seidl M, Tezzon F, et al. Cortical Excitability Changes in Patients with Sleep-Wake Disturbances After Traumatic Brain Injury. Journal of Neurotrauma. 2011; 28: 1165-1171.

104. Shekleton JA, Parcell DL, Redman JR, Phipps-Nelson J, Ponsford JL, Rajaratnam SMW. Sleep Disturbance and Melatonin Levels Following Traumatic Brain Injury. Neurology. 2010; 74: 1732-1738.

105. Skopin MD, Kabadi SV, Viechweg SS, Mong JA, Faden AI. Chronic Decrease in Wakefulness and Disruption of Sleep-Wake Behavior After Experimental TBI. Journal of Neurotrauma. 2015; 32: 289-296.

106. Willie JT, Lim MM, Bennett RE, Azarion AA, Schwetye KE, Brody DL. Controlled Cortical Impact Traumatic Brain Injury Acutely Disrupts Wakefulness and Extracellular Orexin Dynamics as Determined by Intracerebral Microdialysis in Mice. Journal of Neurotrauma. 2012; 29: 19081921

107. Thomasy HE, Febinger HY, Ringgold KM, Gemma C, Opp MR Hypocretinergic and Cholinergic Contributions to Sleep-Wake Disturbances in a Mouse Model of Traumatic Brain Injury. Neurobiology of Sleep and Circadian Rhythms. 2017; 2: 71-84.

108. Rowe RK, Striz M, Bachstetter AD, Van Eldik LJ, Donohue KD, O'Hara, BF, et al. Diffuse Brain Injury Induces Acute Post-Traumatic Sleep. PLOS ONE. 2013; 8: e82507.

109. Modarres MH, Kuzma NN, Kretzmer T, Pack Al, Lim MM. EEG Slow Waves in Traumatic Brain Injury: Convergent Findings in Mouse and Men. Neurobiology of Sleep and Circadian Rhythms. 2017; 2: 59-70.

110. Rowe RK, Harrison JL, O'Hara BF, Lifshitz J. Recovery of Neurological Function Despite Immediate Sleep Disruption Following Diffuse Brain Injury in the Mouse: Clinical Relevance to Medically Untreated Concussion. Sleep. 2014; 37: 743-752.

111. Parcell DL, Ponsford JL, Rajaratnam SMW, Redman JR. Self-Reported Changes to Nighttime Sleep After Traumatic Brain Injury. Archives of Physical Medicine and Rehabilitation. 2006; 87: 278-285.

112. Parcell DL, Ponsford JL, Redman JR, Rajaratnam SMW. Poor Sleep Quality and Changes in Objectively Recorded Sleep After Traumatic Brain Injury: A Preliminary Study. Archives of Physical Medicine and Rehabilitation. 2008; 89: 843-848.

113. Buszaki G, Bickford RG, Ponomareff G, Thal LJ, Mandel R, Gage, FH. Nucleus Basalis and Thalamic Control of Neocortical Activity in the Freely Moving Rat. Journal of Neuroscience. 1998; 8: 4007-4026.

114. Fuller PM, Sherman D, Pederson NP, Saper CB, Lu J. Reassessment of the Structural Basis of the Ascending Arousal System. Journal of Comparative Neurology. 2011; 519: 933-956.

115. Hermann DM, Bassetti CL. Sleep-Related Breathing and Sleep-Wake
Disturbances in Ischemic Stroke. Neurology. 2009; 73: 1313-1322.

116. Rotenberg VS, Indursky P, Kayumov L, Sirota P, Melamed Y. The Relationship Between Subjective Sleep Estimation and Objective Sleep Variables in Depressed Patients. International Journal of Psychophysiology. 2000; 37: 291-297

117. Leppavuori A, Pohjasvaara T, Vataja R, Kaste M, Erkinjuntti T. Insomnia in Ischemic Stroke Patients. Cerebrovascular Disease. 2002; 14: 90-97.

118. Ponsford JL, Parcell DL, Sinclair KL, Roper M, Rajaratnam SMW. Changes in Sleep Patterns Following Traumatic Brain Injury: A Controlled Study. Neurorehabilitation and Neural Repair. 2013; 27: 613-321.

119. Ancoli-Israel S, Alessi C. Sleep and Aging. Am J Geriatr Psychiatry.2005; 13: $341-343$.

120. Young T, Peppard PE, Taheri S. Excess Weight and Sleep-Disordered Breathing. Journal of Applied Physiology. 2005; 99: 1592-1599.

121. Redline S, Kump K, Tishler PV, Browner I \& Ferrette V. Gender Differences in Sleep Disordered Breathing in a Community-Based Sample. American Journal or Respiratory and Critical Care Medicine. 1994; 149: 722-726.

122.Jordan, A.S. \& McEvoy, D. Gender Differences in Sleep Apnea: Epidemiology, Clinical Presentation and Pathogenic Mechanisms. Sleep Medicine Reviews. 2003; 7: 377-389.

123. Imbach LL, Bucjele F, Valko PO, Li T, Maric A, Stover JF, et al. SleepWake Disorders Persist 18 Months After Traumatic Brain Injury but Remain Underrecognized. Neurology. 2016; 86: 1945-1949.

124. Gardani M, Morfiri E, Thomson A, O'Neil B, McMillan TM. Evaluation of Sleep Disorders in Patients with Severe Traumatic Brain Injury During Rehabilitation. Archives of Physical Medicine and Rehabilitation. 2015; 96: 1691-1697.

125. Jones, K. \& Harrison, Y. Frontal Lobe Function, Sleep Loss and Fragmented Sleep. Sleep Medicine Reviews. 2001; 5: 463-475.

126. Cicerone K, Levin H, Malec J, Stuss D, Whyte J. Cognitive Rehabilitation Interventions for Executive Function: Moving from Bench to Bedside in Patients with Traumatic Brain Injury. Journal of Cognitive Neuroscience. 2006; 18: 1212-1222.

127. Bloomfield IL, Espie CA. Do sleep difficulties exacerbate deficits in sustained attention following traumatic brain injury? J Int Neuropsychol Soc. 2010; 16: 17-25.

128. Sinclair KL, Ponsford JL, Rajaratnam SMW, Anderson C. Sustained Attention Following Traumatic Brain Injury: Use of the Psychomotor Vigilance Task. Journal of Clinical and Experimental Neuropsychology. 2013; 35: 210-224.

129. Walker MP, Brakefield T, Morgan A, Hobson JA, Stickgold R. Practice with Sleep Makes Perfect: Sleep-Dependent Motor Skill Learning. Neuron. 2002; 35: 205-211.

130. Walker MP, Stickgold R, Alsop D, Gaab N \& Schlaug G. Sleep-Dependent Motor Memory Plasticity in the Human Brain. Neuroscience. 2005; 13: 911 917.

131. Marshall L, Born J. The contribution of sleep to hippocampus-dependent memory consolidation. Trends in Cognitive Sciences. 2007; 11: 442-450.

132. Makley MJ, English JB, Drubach DA, Kreuz AJ, Celnik PA, Tarwater PM. Prevalence of Sleep Disturbance in Closed Head Injury Patients in a Rehabilitation Unit. Neurorehabilitation and Neural Repair. 2008; 22: 341 347.

133. Clinchot DM, Bogner J, Mysiw JW, Fugate L, Corrigan J. Defining Sleep Disturbance After Brain injury. American Journal of Physical Medicine and Rehabilitation. 1998; 77: 291-295.

134. Wiseman-Hakes C, Murray B, Moineddin R, Rochon E, Cullen N, Gargaro $\mathrm{J}$, et al. Evaluating the Impact of Treatment for Sleep/Wake Disorders on Recovery of Cognition and Communication in Adults with Chronic TBI. Brain Injury. 2013; 27: 1364-1376.

135. Johns MW. A New Method for Measuring Daytime Sleepiness: The Epworth Sleepiness Scale. Sleep. 1991; 14: 540-545. 
136. Van de Water AT, Holmes A, Hurley DA. Objective Measurements of Sleep for Non-Laboratory Settings as Alternatives to Polysomnography--A Systematic Review. Journal of Sleep Research. 2011; 20: 183-200.

137.Ponsford JL, Ziino C, Parcell DL, Shekleton JA, Roper M, Redman JR, et al. Fatigue and Sleep Disturbance Following Traumatic Brain Injury-Their Nature, Causes, and Potential Treatments. The Journal of Headtrauma Rehabilitation. 2012; 27: 224-233.

138. Naeser MA, Saltmarche A, Krengel MH, Hamblin MR, Knight, JA. Improved Cognitive Function After Transcranial, Light-Emitting Diode Treatments in Chronic, Traumatic Brain Injury: Two Case Reports. Photomedicine and Laser Surgery. 2011; 29: 351-358.

139. Morries LD, Cassano P, Henderson TA. Treatments for Traumatic Brain Injury with Emphasis on Transcranial Near-Infrared Laser Phototherapy. Neuropsychiatric Disease and Treatment. 2015; 11: 2159-2175.
140. Goldstein SJ, Wu RHK, Thorpy MJ, Shprintzen RJ, Marion RE, \& Saenger P. Reversibility of Deficient Sleep Entrained Growth Hormone Secretion in a Boy with Achondroplasia and Obstructive Sleep Apnea. Acta Endocrinol. 1987; 116: 95-101.

141. Saini J, Krieger J, Brandenberger G, Wittersheim G, Simon C, \& Follenius M. Continuous Positive Airway Pressure Treatment: Effects of Growth Hormone, Insulin and Glucose Profiles in Obstructive Sleep Apnea. Horm Metab Res. 1993; 25: 375-381

142. Cooper BG, White JE, Ashworth LA, Alberti KG, \& Gibson GJ. Hormonal and Metabolic Profiles in Subjects with Obstructive Sleep Apnea Syndrome and the Effects of Nasal Continuous Positive Airway Pressure (CPAP) Treatment. Sleep. 1995; 18: 172-179.
Phys Med Rehabil Int - Volume 4 Issue 3 - 2017

ISSN : 2471-0377 | www.austinpublishinggroup.com

Kreber et al. (C) All rights are reserved
Citation: Howell SN, Kreber LA, Ashley JG and Griesbach GS. The Influence of Neuroendocrine and Sleep Disturbances on Recovery from Traumatic Brain Injury. Phys Med Rehabil Int. 2017; 4(3): 1122 